\title{
Medical Errors and Patient Safety Education: Views of Intern Doctors
}

\author{
Sultana $\mathrm{M}^{1^{*}}$, Hossain $\mathrm{S}^{2}$, Ara $\mathrm{I}^{3}$, Sultana $\mathrm{J}^{4}$ \\ ${ }^{1}$ Department of Obstetrics and Gynaecology, Shaheed Tajuddin Ahmed Medical College, Gazipur, Bangladesh \\ ${ }^{2}$ Department of Medicine, Shaheed Tajuddin Ahmed Medical College, Gazipur, Bangladesh \\ ${ }^{3}$ Department of Obstetrics and Gynaecology, Popular Medical College \& Hospital, Dhaka, Bangladesh \\ ${ }^{4}$ Department of Obstetrics and Gynaecology, Shaheed Suhrawardy Medical College \& Hospital, Dhaka, \\ Bangladesh
}

\begin{abstract}
Medical errors and patient safety have become increasingly important in the area of medical research in the recent years. World health Organization and other international committees have long been recommending the early integration of education about errors and patient safety in undergraduate and graduate medical education. To integrate patient safety education into existing curriculum views of the doctors towards patient safety education is an important issue. This descriptive type of cross sectional study was carried out to explore the views of intern doctors regarding medical error and patient safety education in undergraduate medical education of Bangladesh. The study was carried out in seven (three public and four private) medical colleges of Bangladesh over a period from July 2014 to June 2015. Study population was 400 intern doctors. Data were collected by self-administered structured questionnaire. The existing curriculum was also reviewed to find out patient safety issues. The study revealed that the topic medical error and patient safety were mostly neglected in the curriculum. But the intern doctors had positive attitude towards patient safety education. A total of $84.8 \%$ of the intern doctors with a high average score of 4.24 agreed that teaching students about patient safety should be a priority in medical students training while $87.8 \%$ agreed that learning about patient safety before graduation from medical colleges would produce more effective doctors. Among the respondents $76.6 \%$ expected more training on patient safety. Almost half of the participants (52.3\%) reported that they had been assigned to tasks for which they were not trained or where medical errors could have happened easily $(57.5 \%)$. From this study it can be concluded that, there was a distinct need for more education and training in the field of medical error and patient safety among the intern doctors.
\end{abstract}

Keywords: Patient safety, Medical error, Intern doctor's view

\section{Introduction}

Patient safety is the prevention of errors and adverse effects to patients associated with health care. Health care has evolved greatly over the past 20 years. But one of the greatest challenges of the $21^{\text {st }}$ Century is not about keeping up with the latest clinical procedures or the latest high-tech equipment. Instead, it is about delivering safer care in complex, pressurized and fast-moving environments.

Since the Harvard study in 1991first described the extent of harm to patients associated with health care. ${ }^{1}$ Many studies confirm that health-care errors are prevalent in our health systems and that the associated costs are substantial. In Australia, errors result in as many as 18000 unnecessary deaths and more than 50000 disabled patients. ${ }^{2}$ In the United States, health-care errors result in at least 44000 (and perhaps as many as 98 000) unnecessary deaths each year, as well as one million excess injuries. ${ }^{3}$ In 2002, WHO member states agreed on a World Health Assembly resolution on patient safety in recognition of the need to reduce the harm and suffering of patients and their families and in acknowledgement of the compelling evidence of the economic benefits of improving patient safety. Studies show that additional hospitalization, litigation costs, infections acquired in hospitals, lost income, disability and medical expenses have cost some countries between US\$ 6 billion and US\$ 29 billion a year. ${ }^{4}$

The extent of patient harm from health care has been exposed by the publication of the international studies of Australia, United States, Canada, England, Denmark and New Zealand. ${ }^{4}$ These studies confirm the large numbers of patients involved and show the adverse event. While the rates of injury differ among the countries that publish data, there is unanimous agreement that the 
harm incurred is of significant concern. The catastrophic deaths that are reported in the media, while horrific for the families and health professionals involved, not representative of the majority of adverse health-care events.

As main providers of health care, doctors are not only involved in the generation of errors, nearmisses and preventable adverse events but also in the prevention and in the follow-up of errors. On the one hand, they are the ones who have to communicate with patients, relatives and colleagues that an error has occurred and have to deal with the consequences of those errors. On the other hand, the physician himself might also be affected and as a second victim, can also be traumatized and suffering from the error. ${ }^{5}$ However, there has been little focus on the education and training of doctors in regard to this topic.

Different international committees have long been recommending the early integration of education about errors and patient safety in undergraduate and graduate medical education. The guideline for curriculum development, which has been introduced in 2008 by the WHO World Alliance for Patient Safety has explicitly created as a guideline for medical faculties. ${ }^{6}$

A topic such as patient safety is not only about instruction of knowledge but also about developing an attitude towards the topic. To approach the challenge of establishing contents and teaching methods, which help to develop students' attitudes, it is important to include the students and the recent graduates and their actual views in the process of curriculum development.

For Bangladesh, no data on student's attitudes towards medical errors and patient safety education has been published so far. Students are not directly involved in patient management before internship. For this reason, this study was designed to explore the views of intern doctors regarding medical error and patient safety education.

\section{Materials and Methods}

This descriptive type of cross sectional study was carried out to explore the views of intern doctors regarding medical error and patient safety education in undergraduate medical education of Bangladesh. The study was conducted in seven (three public and four private) medical colleges of Bangladesh over a period from July 2014 to June 2015, among 400 intern doctors. Those who were available during the study were included.

Document review: 'Curriculum for under graduate medical education in Bangladesh updated in 2012' was reviewed to find out the patient safety issues as out lined by WHO patient safety curriculum guide (11 topics). As WHO patient safety curriculum guide was prepared after 2008 and our previous curriculum was of 2002, so was not reviewed.

Research instrument was self-administered structured questionnaire. In the structured questionnaire a five point Likert scale (1-strongly disagree, 5- strongly agree) was used. It was adapted from the original questionnaire prepared by Carruthers $\mathrm{S}^{7}$ with some modification. Carruthers $\mathrm{S}$ developed this quetionnaire to measure attitude of students and tutors towards patient safety. This questionnaire is developed in such a way that in can be used in a varied context. Out of the 9 issues, 6 issues were taken in this study which were found to be valid and reliable in their study. Some modification was done after pretesting to increase the understandability. The pre-testing of the questionnaire was done on intern doctors who comment on the functionality and comprehensibility of the questionnaire outside the study areas.

The researcher visited the selected medical colleges personally and introduced herself to the principal of the medical colleges and directors of hospital and seek permission to conduct the study. After taking permission from respective authority a brief idea about the study was given to the intern doctors. Verbal consent was taken from them to participate in the study. The researcher herself distributed questionnaire for intern doctors. The intern doctors were briefed about the questionnaire and necessary doubts was clarified by researcher. Most of the intern doctors filled the questionnaire instantly and returned to the researcher but others asked to collect in later on and the researcher did so. As number of intern doctors were more in the public medical colleges 270 sample were taken from three public medical colleges out of 500 . Number of intern 
doctor is less in private medical colleges so 130 sample were taken from private medical college out of 200. Questionnaires were checked after collection and coded manually and were undergone processed and analyzed by using SPSS computer software according to the objective. For each variable frequency distribution and mean score was calculated. Interpretation of the mean score was as follows -

$5=$ strong positive agreement for the statement.

4 to $<5=$ moderate positive agreement for the statement

3 to $<4=$ mild positive agreement for the statement

2 to $<3=$ negative agreement for the statement

1 to $<2=$ strong negative agreement for the

statement

\section{Results}

Out of 400 intern doctors, $56 \%$ were female and $44 \%$ were male. Age of the intern doctors range from 24 to 27 years. Most of the respondents were from government medical colleges. Results of this cross sectional descriptive study were organized into two sections.

Section 1: Contains the result of observation of the existing curriculum. 'Curriculum for under graduate medical education in Bangladesh updated in 2012' was reviewed to find out the patient safety issues. No topic as outlined by WHO patient safety curriculum guide (11 topics) was found in the curriculum. But there were some related issues in different disciplines. These topics mostly cover health team concept, doctor-patient relationship, behavioral science, medical and surgical ethics and infection prevention.

Total teaching learning hour for patient safety issues was only 12 hours (assumed) out of long five years course of 2513 hours. Only a small portion of patient safety issues are there in the curriculum with inadequate time allocated for this. (table I)

Section 2: Structured questionnaire completed by the intern doctors were analysed in this section.
Table I: Distribution of patient safety related issues in the curriculum

\begin{tabular}{|c|c|c|c|}
\hline Subject & Topic/content & $\begin{array}{l}\text { Teaching } \\
\text { method }\end{array}$ & Teaching hour \\
\hline $\begin{array}{l}\text { Community } \\
\text { medicine }\end{array}$ & $\begin{array}{l}\text { Health team } \\
\text { concept } \\
\text { Behavioral } \\
\text { science ,Doctor- } \\
\text { Patient } \\
\text { Relationship }\end{array}$ & $\begin{array}{l}\text { Lecture, } \\
\text { Tutorial } \\
\text { Lecture, } \\
\text { Tutorial }\end{array}$ & $\begin{array}{l}\text { 1hour lecture } \\
\text { \&1hour tutorial } \\
\text { 1hour lecture } \\
\text { \&1hour tutorial } \\
\text { (assumed) }\end{array}$ \\
\hline Medicine & $\begin{array}{l}\text { Doctor- Patient } \\
\text { Relationship, } \\
\text { Medical Ethics, } \\
\text { Patient's safety. } \\
\text { Communication } \\
\text { Skills } \\
\text { Behavioural } \\
\text { Science }\end{array}$ & Lecture & 4 hours $(1 \times 4)$ \\
\hline Surgery & $\begin{array}{l}\text { Surgical ethics } \\
\text { Principles of } \\
\text { asepsis } \\
\text { Universal } \\
\text { precaution } \\
\text { \&O.T.environment } \\
\text { and behavior }\end{array}$ & $\begin{array}{l}\text { Lecture } \\
\text { Lecture } \\
\text { Tutorial }\end{array}$ & $\begin{array}{c}\text { 1hour } \\
\text { 1hour } \\
2 \text { hour }(1 \mathrm{x} 2)\end{array}$ \\
\hline
\end{tabular}

The mean score for this 3 point is 3 - $<4$ i.e. intern doctors have mild positive agreement for the statement. Regarding error reporting confidence mean score for this 3 point is $3-<4$ i.e. intern doctors have mild positive agreement for the statement though the score is low with wide SD (table II). Fifty percent of the intern doctors agreed to report errors $34.3 \%$ disagreed and $15.5 \%$ were neutral. Regarding importance of patient safety in the curriculum, the mean score for this was 4.24 and 4.31 respectively i.e. intern doctors have moderate positive agreement for the statement. Most of the respondents $(87.8 \%)$ agreed that learning about patient safety would produce more effective doctor.

Distribution of the intern doctors by their opinion on working hours as error cause (table III).

The mean score for this was 4 - $<5$ i.e. intern doctors have moderate positive agreement for the statement. Regarding their opinion on error inevitability, the mean score for this was 4.02 i.e. intern doctors have moderate positive agreement for the statement. Most of the respondents (76.3\%) agreed that even the most experienced person can make errors. Regarding their opinion on patient and relatives/carer involvement in reducing error. The mean score for this was 3.96 - 4 i.e intern doctors have mild to moderate positive agreement for the statement. Some Seventy eight percent of the intern doctors agreed that patients and relatives had an important role in preventing medical errors.

It was also revealed that among them $50.5 \%$ had no courses on patient safety. 
Table II: shows the distribution of the intern doctors by their opinion on Patient safety training received.

\begin{tabular}{|c|c|c|c|c|c|c|}
\hline & $\begin{array}{c}1 \\
\text { Strongly } \\
\text { Disagree } \mathrm{f}(\%)\end{array}$ & $\begin{array}{c}2 \\
\text { Disagree } \\
\mathbf{f}(\%)\end{array}$ & $\begin{array}{c}3 \\
\text { Neither agree nor } \\
\text { disagree } f(\%)\end{array}$ & $\begin{array}{c}4 \\
\text { Agree } \\
\mathbf{f}(\%)\end{array}$ & $\begin{array}{c}5 \\
\text { Strongly } \\
\text { Agree } \mathbf{f}(\%)\end{array}$ & $\begin{array}{l}\text { Mean } \\
(\text { SD } \pm)\end{array}$ \\
\hline \multicolumn{7}{|l|}{ Patient safety training received } \\
\hline $\begin{array}{l}\text { My training is preparing me to understand the } \\
\text { causes of medical errors. }\end{array}$ & $14(3.5)$ & $64(16)$ & $129(32.3)$ & $155(38.8)$ & $38(9.5)$ & $\begin{array}{l}3.35 \\
.974\end{array}$ \\
\hline $\begin{array}{l}\text { I have a good understanding of patient safety issues } \\
\text { as a result of my undergraduate medical training. } \\
\text { Error reporting confidence }\end{array}$ & $8(2)$ & $125(31.3)$ & $88(22)$ & $138(34.5)$ & $41(10.3)$ & $\begin{array}{c}3.20 \\
1.054\end{array}$ \\
\hline $\begin{array}{l}\text { My training is preparing me to prevent medical } \\
\text { errors. }\end{array}$ & $23(5.8)$ & $118(29.5)$ & $82(20.5)$ & $137(34.3)$ & $40(10)$ & $\begin{array}{c}3.13 \\
1.119\end{array}$ \\
\hline $\begin{array}{l}\text { I would feel comfortable reporting any errors I had } \\
\text { made, no matter how serious the outcome had been } \\
\text { for the patient }\end{array}$ & $72(18)$ & $65(16.3)$ & $62(15.5)$ & $161(40.4)$ & $40(10)$ & $\begin{array}{l}3.08 \\
1.297\end{array}$ \\
\hline $\begin{array}{l}\text { I would feel comfortable reporting any error other } \\
\text { people had made, no matter how serious the } \\
\text { outcome had been for the patient }\end{array}$ & $61(15.3)$ & $86(21.5)$ & $74(18.5)$ & 144(36) & $35(8.8)$ & $\begin{array}{c}3.02 \\
1.240\end{array}$ \\
\hline \multicolumn{7}{|l|}{ Importance of patient safety in the curriculum } \\
\hline $\begin{array}{l}\text { Teaching students about patient safety should be an } \\
\text { important priority in medical students training }\end{array}$ & $4(1)$ & $2(.5)$ & $55(13.8)$ & $173(43.3)$ & $166(41.5)$ & $\begin{array}{l}4.24 \\
.779\end{array}$ \\
\hline $\begin{array}{l}\text { Learning about patient safety issues before I } \\
\text { qualify will enable me to become a more effective } \\
\text { doctor }\end{array}$ & $2(.5)$ & $7(1.8)$ & $40(10)$ & $169(42.3)$ & $182(45.5)$ & $\begin{array}{l}4.31 \\
.761\end{array}$ \\
\hline
\end{tabular}

Table III: Distribution of the intern doctors by their opinion on working hours as error cause, error inevitability, patient and relatives/carer involvement in reducing error $(\mathrm{n}=400)$

\begin{tabular}{|c|c|c|c|c|c|c|}
\hline & $\begin{array}{c}1 \\
\text { Strongly } \\
\text { disagree } \mathrm{f}(\%)\end{array}$ & $\begin{array}{c}2 \\
\text { Disagree } \\
\mathbf{f}(\%)\end{array}$ & $\begin{array}{c}3 \\
\text { Neither agree nor } \\
\text { disagree } \mathbf{f}(\%)\end{array}$ & $\begin{array}{c}4 \\
\text { Agree } f(\%)\end{array}$ & $\begin{array}{c}5 \\
\text { Strongly } \\
\text { Agree } \mathbf{f}(\%)\end{array}$ & $\begin{array}{l}\text { Mean } \\
(\mathrm{SD} \pm)\end{array}$ \\
\hline \multicolumn{7}{|l|}{ Working hours as error cause } \\
\hline $\begin{array}{l}\text { Shorter shifts for doctors will reduce medical } \\
\text { errors on the other hand number of hours doctors } \\
\text { work increases the likelihood of making medical } \\
\text { errors }\end{array}$ & $6(1.5)$ & $13(3.3)$ & $50(12.5)$ & 190(47.5) & $141(35.3)$ & $\begin{array}{l}4.12 \\
.855\end{array}$ \\
\hline $\begin{array}{l}\text { By not taking regular breaks during shifts, } \\
\text { doctors are at an increased risk of making errors. } \\
\text { Error inevitability }\end{array}$ & $5(1.3)$ & $6(1.5)$ & $34(8.5)$ & $178(44.5$ & $177(44.3)$ & $\begin{array}{l}4.29 \\
.786\end{array}$ \\
\hline $\begin{array}{l}\text { Even the most experienced and competent } \\
\text { doctors make errors and human error is } \\
\text { inevitable }\end{array}$ & $3(.8)$ & $14(3.5)$ & $78(19.5)$ & $182(45.5)$ & $123(30.8)$ & $\begin{array}{l}4.02 \\
.846\end{array}$ \\
\hline \multicolumn{7}{|c|}{ Patient and relatives/carer involvement in reducing error } \\
\hline $\begin{array}{l}\text { Patients and relatives have an important role in } \\
\text { preventing medical errors }\end{array}$ & $3(.8)$ & $22(5.5)$ & $65(16.3)$ & $210(52.6)$ & $100(25)$ & $\begin{array}{l}3.96 \\
.836\end{array}$ \\
\hline $\begin{array}{l}\text { Encouraging patients and relatives to be more } \\
\text { involved in their care can help to reduce the risk } \\
\text { of medical errors occurring }\end{array}$ & $8(2)$ & $8(2)$ & $62(15.5)$ & $219(54.8)$ & $103(25.8)$ & $\begin{array}{l}4.00 \\
.821\end{array}$ \\
\hline
\end{tabular}

Table IV: Distribution of the intern doctors by their opinion on education system ( $\mathrm{n}=400)$

\begin{tabular}{lcc}
\hline \multicolumn{1}{c}{ Different events related to education system } & \multicolumn{2}{c}{ Frequency (\%) } \\
& Yes (\%) & No (\%) \\
\hline During my medical education, I had courses regarding patient safety & $195(49.5)$ & $199(50.5)$ \\
During my medical education, I had courses regarding errors in medicine & $165(41.9)$ & $229(58.1)$ \\
During my internship, I came in contact with medical errors and their disclosure & $183(45.8)$ & $217(54.3)$ \\
I wish I would have had more education/teaching on patient safety and medical error & $301(76.6)$ & $92(23.4)$ \\
I made a medical error on my own & $165(41.3)$ & $235(58.8)$ \\
During my Internship, I was assigned to tasks I was not trained for & $209(52.3)$ & $191(47.8)$ \\
During my internship, I was assigned to tasks, which could easily have resulted in medical errors. & $226(57.5)$ & $167(42.5)$ \\
\hline
\end{tabular}




\section{Discussion}

Patient safety is a new concept worldwide. There are different studies in different countries of the world in this topic. WHO Patient Safety Curriculum Guide: Multi-professional Edition seeks to fill the gap in patient safety education by providing a comprehensive curriculum designed to build foundation knowledge and skills for all health-care students that will better prepare them for clinical practice in a range of environments. ${ }^{4}$ This curriculum guide provides 11 ready to teach patient safety topic. Curriculum for under graduate medical education in Bangladesh updated in 2012 was reviewed to find out these topics. But only minor aspects like the term patient safety, infection prevention, health team concept, doctor patient relationship, and medical ethics were there. But the teaching hour was also inadequate. There was no appropriate assessment plan for these topics. Integration of WHO guidelines had not been done yet. Integration of this into existing curriculum of different countries require appropriate attitude of the health care professional.

Most of the respondents in this study showed a positive attitude toward patient safety. This is similar to PHCC doctors in Aseer region showing a positive attitude toward patient safety. ${ }^{8}$

Regarding their opinion on Patient safety training received. The mean score for this 3 point is 3 to $<4$ i.e intern doctors have mild positive agreement for the statement. This finding is similar to the findings of Al-Khaldi. ${ }^{8}$

Reporting medical errors is an important step in improving the quality of health-care including patient safety. Means core of the participants on this item was 3.08 and 3.02. This finding is similar to the findings in other study. ${ }^{8}$ These low scores which reflected the negative attitude of some physicians toward reporting adverse events could be due to the lack of a system for reporting medical errors. Also, a culture of safety in health settings, as reported by Alahmadi is yet to be developed. ${ }^{9}$ As reported by Hammami et al the disclosure of medical errors poses a big dilemma in health settings in Saudi Arabia. ${ }^{10}$ In this study $50.4 \%$ of the intern doctors agreed to disclose error while $34.3 \%$ disagreed and $15.5 \%$ were neutral. In another study, the trend was similar as $44 \%$ agreed that "doctor had the responsibility of disclosing errors to patients only if they resulted in harm to the patient," while $40 \%$ disagreed and $16 \%$ were neutral. ${ }^{8}$ A study of medical trainees done by Sorokin found that $80 \%$ would disclose adverse events to patients. ${ }^{11}$ In a study in Italy $44.5 \%$ physicians agreed and $44.1 \%$ were uncertain about the disclosure of errorstopatient. ${ }^{12}$ These diversity of attitude could be explained by the lack of training and experience of physician in dealing with medical errors. In addition, there is a lack of established culture of reporting adverse events by the physician himself in Bangladesh. This finding is similar to the findings in PHC settings in Saudi Arabia. ${ }^{8}$

In this study interns thought shorter shift for doctors would reduce the error. In the few PHCC with a high number of patients attending and work overload, participants showed that a shorter shift for the doctors and taking breaks would reduce medical error. ${ }^{8}$ These findings agree with those reported in 2009 by Carruthers et al. ${ }^{7}$

In this study the area of error inevitability point, most of the intern doctors agreed that even the most experienced can make errors. This area scored positively and is similar to other study. The area of "errors inevitability" scored 3.97-4.31 points. The finding similar to the findings of Al-Khaldi. ${ }^{8}$ These findings are also comparable to those reported from UK by Carruthers. ${ }^{7}$

Patients play an essential role in their health and safety by active involvement in decision making and self-management. ${ }^{13}$ In this study, intern doctors (77.6\%) had positive agreement that patients and relatives had important role in reducing error. Primary health care centre physicians in Aseer region showed average to high agreement $(84 \%)$ in this regard (4.9 and 5.9 points $)^{8}$ compared to 5.2 points in UK study ${ }^{7}$, but less than what was reported from Saudi Arabia (44.7\%) by Hammami et al. ${ }^{10}$

The last theme of the study was about the importance of patient safety in the curriculum. A total of $84.8 \%$ of the intern doctors with a high average score of 4.24 out of five points agreed that teaching students about patient safety is a priority in medical training while $87.8 \%$ with the highest score of all items in the questionnaire agreed that learning about patient safety before graduation from medical colleges would produce more effective doctors. This finding is similar to Al-Khaldi which showed $90 \%$ and $84 \%$ positive 
response for the two items respectively. ${ }^{8}$ These important findings are also in agreement with results of two studies conducted among medical students in the Qassim region by Almaramhy and Hong Kong by Leung \& Patil which emphasized the priority of putting patient safety in the undergraduate curriculum of medical colleges. ${ }^{14,15}$ Students regarded patient safety as an important topic that should be included in undergraduate teaching and professional examinations. ${ }^{15}$

In this study, $50.5 \%$ of intern doctors had no training on patient safety and $58.1 \%$ of them had no training about medical error. In a study in Germany, $79.8 \%$ of the respondent had no training on patient safety and $83.2 \%$ of the respondent had no training on medical error. ${ }^{5}$ In a study in Aseer region in Saudi Arabia, 70\% had not attended any training course on patient safety. ${ }^{8}$ Such important findings indicate that there is urgent need for such interventions as conducting continuous professional development programs on "medical errors and patient safety" for intern doctors. In spite of the importance of patient safety in the medical curriculum, in this study $76.6 \%$ of the intern doctors were not satisfied with their learning or training and they wished more training on patient safety. In a study in Germany, majority of respondents (64\%) wished for more education on the issues. ${ }^{5}$

A study by Almaramhy et al mentioned that more than two-thirds of medical students agreed that the teaching of patient safety in medical schools and the continuous training of health staff was necessary. ${ }^{14}$ These findings should alert us on the issue of the curriculum of medical colleges in Bangladesh and the importance of making "patient safety and medical errors" a priority in the curriculum particularly in final years.

In this study, $41.3 \%$ of intern doctors stated that they had already committed a medical error. In a study by Kiesewetteretal, $25 \%$ of the students stated that they already had committed a medical error. ${ }^{5}$ Almost half of the participants reported that they had been assigned to tasks for which they were not trained $(52.3 \%)$ or where medical errors could have happened easily $57.5 \%$. This finding is similar to the study in Germany conducted by Kiesewetter et al. ${ }^{7}$ which showed $49.7 \%$ and $55.5 \%$ respectively. ${ }^{5}$

\section{Conclusion}

In this study the intern doctors had positive attitude towards patient safety education. Most of the respondents considered patient safety as a priority topic for undergraduate medical education. Among the intern doctors there was a distinct need for more training in the field of medical error and patient safety. They did not feel sufficiently trained for working as physicians especially in dealing with errors and their communication Existing curriculum was not sufficient for teaching patient safety.

\section{References}

1. Brennan TA, Leape LL, Laird NM, Hebert L, Localio AR, Lawthers A. Incidence of adverse events and negligence in hospitalized patients: results of theHarvard Medical Practice Study.NEngl J Med 1991;324:370-76

2. Weingart SN, Wilson RM, Gibberd RW, HarrisonB. Epidemiology of medical Error.BMJ2000; 320:77477.

3. Kohn LT, Corrigan JM, Donaldson MS. To err ishuman: Building a safer health system. Washington, DC, Committee on Quality of Health Care in America, Institute of Medicine, National Academies Press, 1999.

4. World Health Organization 2011. WHO patient safety curriculum guide: multi- professional edition. available at (www.who.int)

5. Kiesewetter J, Kager M, Lux R, Zwissler B, Fischer MR, Dietz I. German undergraduate medical students'attitudes and needs regarding medical errors and patient safety - A national survey in Germany. Medical Teacher2014;36:505-10.

6. World alliance for patient safety (2008) - World Health Organization.Retrived from http://www.who.int/patientsafety/information_centr e/reports/Alliance

7. Carruthers S, Lawton R, Sandars J, Howe A, Perry M. Attitudes to patient safety amongst medical students and tutors: Developing a reliable and valid measure. Medical Teacher, 2009;31:.e370-e376.

8. Al-KhaldiYM.Attitude of primary care physicians toward patient safety in Aseer region, Saudi Arabia. JFamCommunity Med, 2013; 20:153-8.

9. Alahmadi HA. Assessment of patient safety culture in Saudi Arabian hospitals. QualSafHealth Care, 2010;19:e17

10. Hammami MM, Attalah S, AlQadire M. Which medical error to disclose to patients and by whom? Public preference and perceptions of norm and current practice', BMC Med Ethics, 2010;11:17

11. Sorokin R, Riggio JM, Hwang C. Attitudes about patient safety: A survey of physicians-in-training. Am J Med Qual, 2005;20:70-76 
12. Flotta D, Rizza P, Bianco A, Pileggi C, Pavia M. Patient safety and medical errors: knowledge, attitudes and behavior among Italian hospital physicians. Int J Qual Health Care. $2012 ; 24: 258-65$

13. PhillipsRL, The Health Care Policy Context. In: Sandars J, Cook G,editor. ABC of Patient Safety. Blackwell Publishing; 2007 p. 3

14. Almaramhy $\mathrm{H}$, Al-Shobaili H, El-Hadary $\mathrm{K}$, DandashK. Knowledge and attitude towards patient safety among a group of undergraduate medical students in Saudi Arabia, International Journal of Health Science (Qassim), 2011;5:59-67

15. Leung GK, Patil NG. Patient safety in the undergraduate curriculum: Medical student's perception. Hong Kong Med J 2010;16:101-05

*Correspondence: Mahmuda Sultana, Department of Obstetrics and Gynaecology, Shaheed Tajuddin Ahmed Medical College Hospital, Gazipur, Bangladesh; e-mail: smahmuda777@yahoo.com 